\title{
Substorms during different storm phases
}

\author{
N. Partamies ${ }^{1}$, L. Juusola ${ }^{1}$, E. Tanskanen ${ }^{1,2}$, K. Kauristie ${ }^{1}$, J. M. Weygand ${ }^{3}$, and Y. Ogawa ${ }^{4}$ \\ ${ }^{1}$ Finnish Meteorological Institute, Helsinki, Finland \\ ${ }^{2}$ University of Bergen, Bergen, Norway \\ ${ }^{3}$ University of California, Los Angeles, USA \\ ${ }^{4}$ National Institute of Polar Research, Tokyo, Japan
}

Received: 15 March 2011 - Revised: 18 August 2011 - Accepted: 3 October 2011 - Published: 17 November 2011

\begin{abstract}
After the deep solar minimum at the end of the solar cycle 23, a small magnetic storm occurred on 20-26 January 2010. The Dst (disturbance storm time) index reached the minimum of $-38 \mathrm{nT}$ on 20 January and the prolonged recovery that followed the main phase that lasted for about 6 days. In this study, we concentrate on three substorms that took place (1) just prior to the storm, (2) during the main phase of the storm, and (3) at the end of the recovery of the storm. We analyse the solar wind conditions from the solar wind monitoring spacecraft, the duration and intensity of the substorm events as well as the behaviour of the electrojet currents from the ground magnetometer measurements. We compare the precipitation characteristics of the three substorms.

The results show that the F-region electron density enhancements and dominant green and red auroral emission of the substorm activity during the storm recovery resembles average isolated substorm precipitation. However, the energy dissipated, even at the very end of a prolonged storm recovery, is very large compared to the typical energy content of isolated substorms. In the case studied here, the dissipation of the excess energy is observed over a 3-h long period of several consecutive substorm intensifications. Our findings suggest that the substorm energy dissipation varies between the storm phases.
\end{abstract}

Keywords. Magnetospheric physics (Magnetosphereionosphere interactions; Solar wind-magnetosphere interactions; Storms and substorms)

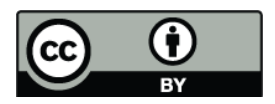

Correspondence to: N. Partamies (noora.partamies@fmi.fi)

\section{Introduction}

As magnetic storms and substorms were identified very early on in the 1970s (McPherron, 1970), the substorms were recognized as not only one of the main mechanisms for transporting energy from the magnetotail into the ionosphere, but also for dissipating the storm energy. However, the relationship between the storms and substorms is still rather poorly known, and how exactly the isolated quiet time substorms differ from the storm-time substorm activity is not very well understood. This is mainly due to the ease of studying quiet time substorms without the interference of other disturbances, as compared to the complex storm-time activations that are also named substorms but have not been characterised in detail.

The typical length of the substorm cycle is about $2-4 \mathrm{~h}$. It includes the phases of growth, expansion and recovery, whose durations vary from the short expansion of 15-20 min to a lengthy growth or recovery of a few hours (Tanskanen, 2009; Gjerloev et al., 2007). Similar durations of 1.3-2.3 h for the combination of expansion and recovery phases were found by Kullen and Karlsson (2004) in a survey of global auroral images from the Polar spacecraft. The growth phase cannot be reliably determined from the global images, so it was excluded from their study. The average duration of substorms observed in 1993-2003 by Tanskanen (2009) is about $3 \mathrm{~h}$, while the full range of the yearly averages varied from 2.75 to $3.3 \mathrm{~h}$. Tanskanen (2009) defined the onset from the decrease of a local electrojet (IL) index (IL indices, Kallio et al., 2000). The decrease was required to be at least $100 \mathrm{nT}$ and the rate of decrease more than $80 \mathrm{nT}$ in $15 \mathrm{~min}$. The start of the substorm growth was defined as when IL index showed the first signs of a negative bay, but not more than $30 \mathrm{~min}$ before the onset time. The substorm was believed to be over when the IL index had recovered $80 \%$ of the peak deflection. In 1997, the average substorm duration was 15-20 min

Published by Copernicus Publications on behalf of the European Geosciences Union. 
shorter than the mean value of $3 \mathrm{~h}$ for all 11 years. The length of the substorm period also increased slightly towards the year 2003. The average substorm duration in 2003 represents the average duration of substorms during solar maximum. A similar time cadence of $2-3 \mathrm{~h}$ has been reported as the substorm recurrence rate (e.g. Borovsky et al., 1993; Pulkkinen et al., 2007).

The repetitive substorms are often related to magnetic storms. The storms are longer-term geomagnetic activity periods for which Dst index reaches a minimum of at least $-40 \mathrm{nT}$ (Kallio et al., 2000). An early storm model by Gonzalez et al. (1994) examines the ring current enhancement, as measured by Dst index, with a superposition of a number of substorm disturbances. This simple formulation results in a conclusion that, apart from the most intense and frequent substorms taking place during storm main phases (the interval of largest decrease of Dst index), there are no apparent differences between quiet time and storm-time substorms. The storm initial phase is often believed to start with a solar wind trigger, which for intense storms tends to be an interplanetary shock front. The storm main phase is typically accompanied by sustained southward Interplanetary Magnetic Field (IMF), and the storm recovery phase lasts until the magnetosphere has returned to nominal conditions and dissipated most of the excess energy delivered by the solar wind.

The main solar wind drivers of geomagnetic storms are Interplanetary Coronal Mass Ejections (ICME), and HighSpeed Streams (HSS) and Co-rotating Interaction Regions (CIR). While a CIR forms a shock in the solar wind, it is typically followed by a HSS. CMEs are more frequent during high solar activity. HSS/CIR drivers are associated with coronal holes, and they are the dominant drivers of geomagnetic disturbances in the declining phase of the solar cycle (e.g. Tsurutani et al., 2006, and references therein). Longlived coronal holes result in recurring geomagnetic activity with the period of the solar rotation (about 27 days). The geomagnetic activity induced by CMEs is typically more intense (more negative Dst), while HSS/CIR driven disturbances are weak to moderate but long-lasting (Turner et al., 2009; Denton et al., 2006). However, as demonstrated by Turner et al. (2009), the CIR caused storms are more geoefficient as compared with CME driven activity. In particular, ionospheric dissipation has a more pronounced role in the energy partitioning during the CIR storms (higher $\mathrm{Kp} / \mathrm{AE}$ ) than during the CME storms. At the Earth's distance from the Sun, the evolving CIRs are often called stream interfaces or CIR stream interfaces (Gosling et al., 1978). In the declining phase of the solar cycle, the occurrence of stream interfaces has been shown to correlate with the occurrence of Steady Magnetospheric Convection (SMC) events, so that the maximum in SMC occurrence takes place about 0.5-1 days after the stream interface encounter (Kissinger et al., 2011).

While the concept of an isolated substorm is widely studied, the least investigated aspect is the more complex activity during geomagnetic storms. The higher level of global activity (measured by Kp or Dst) during storms makes it difficult to identify some of the aspects associated with isolated substorms. Comparison of isolated and storm-time substorms by Tanskanen et al. (2002a) showed that the storm-time substorms consume about three times as much energy as the isolated substorms do. The energy dissipation was investigated in terms of ionospheric Joule heating that averaged to $0.3 \times 10^{15} \mathrm{~J}$ for the isolated events and $1.0 \times 10^{15} \mathrm{~J}$ for the storm-time events. However, the large storm-time Joule heating value only accounts for about $1 / 5$ of the total energy consumption of the storm-time substorm, while the corresponding fraction for the isolated substorms is $1 / 3$. From this finding it follows that isolated substorms tend to be less intense but use the available solar wind energy more efficiently. The mean magnetic deflection of the isolated substorms in 1997 and 1999 was found to be $-350 \mathrm{nT}$, while the yearly average values range from -300 to $-500 \mathrm{nT}$. The typical intensity (maximum deflection of the IL index) of stormtime substorm events was $-670 \mathrm{nT}$, with a full range from -200 to $-1800 \mathrm{nT}$ (Tanskanen et al., 2002b). During the solar minimum years 1997 and 1999, isolated substorms were five times as frequent as storm-time substorms. All examined substorms lasted about $4 \mathrm{~h}$ on average. Since the storm event studied in this paper took place only a year after the solar minimum, the statistical results of the years 1997 and 1999 around the previous solar minimum provide realistic reference values for our results.

An investigation of global auroral activity during stormtime substorms (Hoffman et al., 2010) utilized the Visible Imaging System (VIS, Frank et al., 1995) and the Ultraviolet Imaging System (UVI, Torr et al., 1995) on the Polar spacecraft to characterise the differences between isolated and storm-time substorms. It was found that the storm-time substorm onsets occur, on average, at about 4 degrees lower latitudes than the isolated substorms. The storm-time events experienced an average expansion phase of $15 \mathrm{~min}$, while isolated substorm expansions typically went on for about $30 \mathrm{~min}$. The auroral emission intensity during storm-time events was approximately twice that of the isolated events.

A recent study by Pulkkinen et al. (2007) presented a statistical comparison of typical solar wind driver conditions and ionospheric activity for sawtooth events and substormlike auroral electrojet activations during geomagnetic storms. They concluded that substorm-like storm-time activations (Dst $\leq-50 \mathrm{nT}$ ) behave very similar to sawtooth events: the 2-3 h periodicity, strong stretching of the dusk sector field, and strongly asymmetric ring current were found in association with both event types. They demonstrated that the level of driving is very similar during sawtooth events and other storm-time activations, while the auroral activity (AL) index is slightly lower in the case of sawtooth events. Furthermore, Partamies et al. (2009) suggested that the key parameter in determining the type of magnetospheric response to the solar wind driving is the the solar wind speed. For fast flows, 


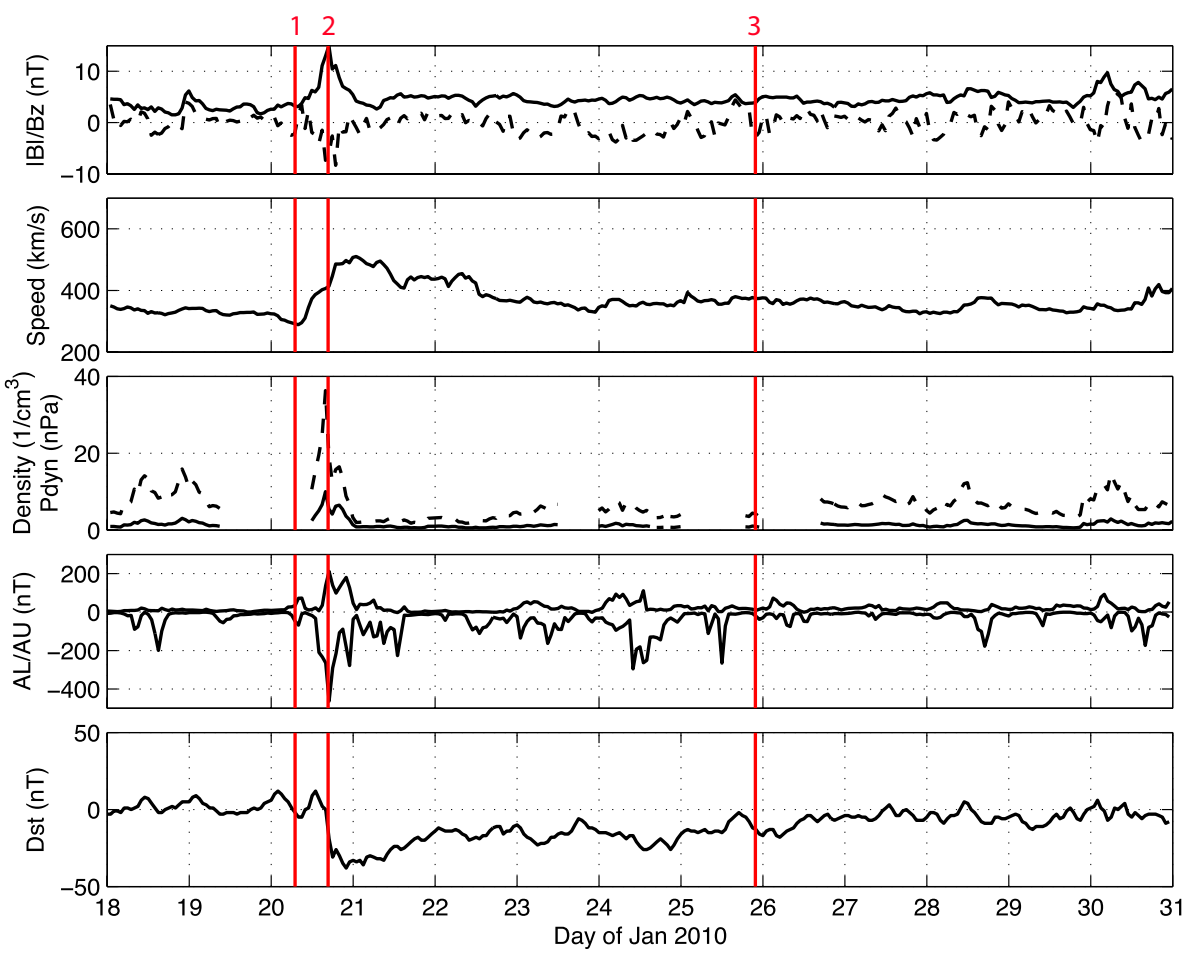

Fig. 1. Solar wind and global indices during 13 days of January 2010. Panels from top to bottom: IMF magnitude and IMF $B_{Z}$ component (dashed line), solar wind speed, dynamic pressure and number density (dashed line), AL/AU indices, and Dst index. Red vertical lines mark the substorm events examined in this study with the corresponding substorm number on the top.

loading-unloading cycles (substorms and sawtooth events) are more likely to occur, while slower solar wind tends to drive SMC activity. SMCs and isolated substorms were also found to use the solar wind energy more efficiently than the more intensely driven events.

What remains mostly uncharacterised are the substorm properties during different storm phases. This question motivates our study. We examine a single small magnetic storm after a prolonged solar minimum in which we identify three substorms: pre-storm (substorm 1), main phase (substorm 2) and recovery (substorm 3). We consider this small storm to be indicative of a state between quiet time and typical stormtime geomagnetic activity.

\section{Event and data descriptions}

We analyse three substorms during a magnetic mini-storm in January 2010. The latest solar minimum (cycle 23) was longlasting and extremely quiet (Pulkkinen et al., 2011). The first storm of the rising phase was weak, with the Dst minimum of $-38 \mathrm{nT}$ (Fig. 1). This Dst minimum falls just short of the Dst definition of a storm (Dst $\leq-40 \mathrm{nT}$ ). Thus it can be described as a small magnetic storm, or magnetic mini-storm. However, this mini-storm in January 2010 appears to have had an extremely long recovery that lasted about 6 days instead of the nominal 1-3 day duration. We define the storm to have lasted until Dst levelled to its pre-storm value or recovered at least $80 \%$ of its minimum (Dst $>-8 \mathrm{nT}$ ) on 2627 January. The slow recovery of the Dst index during magnetic storms during solar minimum has already been reported by Tsurutani and Gonzalez (1997). They concluded that the frequent particle injections during prolonged intervals of intense auroral electrojet activity prohibits the ring current decay.

As is often true for geomagnetic disturbances during the quiet years of the solar activity, the mini-storm is related to the solar wind stream from a coronal hole. The time evolution of the IMF magnitude and its Z-component, solar wind speed, density and pressure are shown in top panels of Fig. 1. An enhancement of IMF magnitude, solar wind pressure and density closely followed by an increase of the solar wind speed at the beginning of the mini-storm is a signature of a stream interface compression region. Stream interfaces where the faster stream from the coronal hole interacts with the slower flow are typically observed at the Earth's distance from the Sun instead of a fully developed CIR (Tsurutani et al., 2006). The timing of the compression suggests that the mini-storm main phase was triggered by this stream interface.

For each of the three substorms during this mini-storm, we examine the solar wind and IMF conditions from the Advanced Composition Explorer (ACE) spacecraft at the L1 


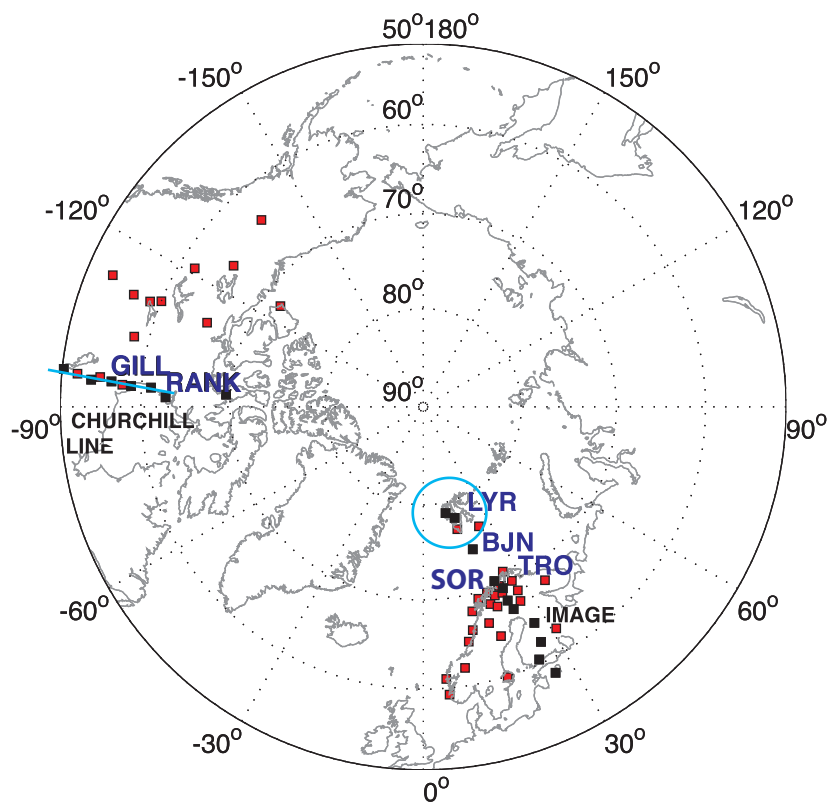

Fig. 2. Meridionally selected magnetometer stations of the IMAGE and CARISMA networks (black diamonds) that were used for the calculations of 1-D equivalent currents are plotted on the map. The meridional CARISMA line is frequently referred to as the Churchill line. Red and black diamonds together mark the stations of IMAGE and CARISMA networks (all available) that were used to calculate the local electrojet indices IL/IU and CL/CU, respectively. The optical and radar stations used in this study are labelled. The cyan circle and line mark the fields-of-view of an all-sky camera and meridian scanning photometer that are also used in this study. Stations that are closest to the onset locations and that are mentioned in the text are also labelled on the map.

point in the upstream solar wind with the temporal resolution of $64 \mathrm{~s}$. The dynamic pressure and epsilon parameter (Perreault and Akasofu, 1978) as a measure of the solar wind energy input are calculated from these measurements. All ACE data have been propagated to the magnetopause (to the distance of $10 R_{\mathrm{E}}$ upstream of the Earth) using the upstream distance of the spacecraft from the magnetopause and the average radial component of the solar wind $\left(V_{\mathrm{X}}\right)$ during the interval of interest.

The geomagnetic equatorial Dst index is used to identify and characterise the mini-storm and its time evolution. Ground magnetic field recordings from International Monitor for Auroral Geomagnetic Effects (IMAGE, Viljanen and Häkkinen, 1997) are analysed for the substorm events on the European side, and Canadian Array for Realtime Investigations of Magnetic Activity (CARISMA, formerly known as CANOPUS Rostoker et al. (1995)) for the event in the North-American sector. These data are used to calculate the local electrojet indices, IL/IU for IMAGE and CL/CU for CARISMA, as well as to estimate the ionospheric equivalent currents in the substorm activity region. IMAGE chain has a limited local time coverage, while CARISMA's station density (spatial recolution) is low. We selected events where the onsets occurred close to a single magnetometer station. Some uncertainty is still inevitable in determining the onset time and location.

One-dimensional electrojet current density has been determined by a method of spherical elementary current systems (Vanhamäki et al., 2003). Magnetometer stations of IMAGE and CARISMA, which were used in 1-D equivalent current calculations, are shown (black diamonds) on the map in Fig. 2. Also marked are all the other local electrojet index stations (red diamonds). The optical and radar stations mentioned in the text have also been labeled on the map.

We use 2-D equivalent current maps of the substorm onset regions to infer the equivalent current pattern around the activity region (Amm, 1997; Amm and Viljanen, 1999; Weygand et al., 2011). On the North-American side (for substorm 1) the method utilises CARISMA, STEP Polar Network, Time History of Events and Macroscale Interactions during Substorms (THEMIS), Greenland, Magnetometer Array for Cusp and Cleft (MACCS, Northern Canada (Engebretson et al., 1995)) and Canadian Magnetic Observatory System (CANMOS Eastern Canada) data. Due to the very different scales and station densities of the Fennoscandian and North-American arrays, the resulting 2-D current maps also have different spatial resolutions. The purpose of the 2-D current maps is to provide the large-scale current configuration and is not meant to give detailed insight into the flows.

Particle precipitation during the substorms are evaluated from the European Incoherent Scatter (EISCAT) UHF radar measurements at Troms $\emptyset$ and Longyearbyen, Svalbard. Auroral emission intensity is measured by the Magnetometers - Ionospheric Radars - All-sky Cameras Large Experiment (MIRACLE, Syrjäsuo et al., 1998) auroral cameras, and the NORthern Solar Terrestrial ARray (NORSTAR, Donovan et al., 2003) Meridian Scanning Photometer (MSP) at Gillam. These data are used whenever available.

For each of the substorms we also examined the Super Dual Auroral Radar Network (Greenwald et al., 1995) ionospheric convection data at the location of the activity. We specifically identified the separation between the Harang reversal region and the substorm onset. Here, we refer the midnight transition region between the dusk and dawn cell as Harang reversal. The plasma flow maps are not shown in this study.

The substorm events are selected based on the data coverage. Especially during the storm recovery, there are substorms each day. We selected the storm recovery substorm as much towards the end of the mini-storm as possible. We also required the EISCAT radar measurements in order to compare the precipitation characteristics between the storm main phase and the storm recovery phase. EISCAT radar provides higher spatial and temporal resolution and much less coverage than the other instruments used in this study. Therefore, 

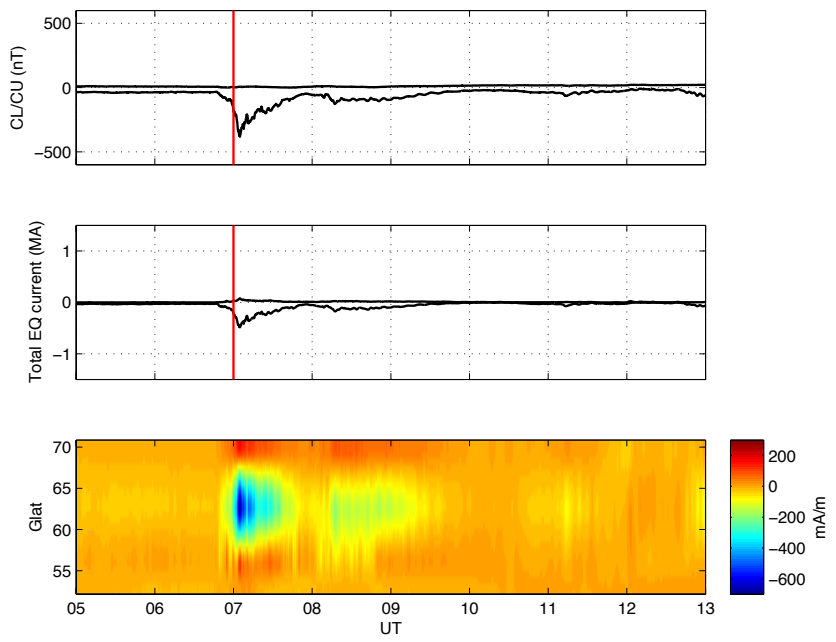

Fig. 3. Ground-based measurements during the pre-storm substorm (substorm 1) as a function of Universal Time. Panels from top to bottom: (1) Auroral electrojet index (upper and lower) calculated from the Churchill line of the CARISMA chain, (2) strength of the total electrojet currents (eastward positive, westward negative) estimated from the magnetometer data, and (3) electrojet current density deduced from magnetometer recordings by 1-D upward continuation method (green/blue colours for westward and yellow/red colours for eastward).

the radar data are not used for timing purposes of the substorm onsets but only to probe the expansion related precipitation.

We identify the substorm onsets from the magnetometer data as abrupt decreases of the X-component. The latitude of the station that shows this signature first is taken as the latitude of the onset. The time of this onset signature is used to calculate the substorm onset time in Magnetic Local Time (MLT). We define the period prior to the substorm onset where the magnetic X-component of the corresponding station slowly decreases as the growth phase, which is not limited in duration. The recovery phase lasts until the magnetic X-component has returned to its pre-substorm level or at least $80 \%$ of the $B_{\mathrm{X}}$ minimum.

Many studies use the southward turning of the IMF $B_{\mathrm{Z}}$ as an indicator of the beginning of the growth phase. That approach gives a good global estimate for the substorm onset. This does not hold for all substorms since some substorms occur during northward IMF (Hsu and McPherron, 2003; Kullen and Karlsson, 2004). All three substorms of the present study are associated with more typical southward IMF conditions. Furthermore, our definitions of substorm phases only use ground-based data and thus, we look for substorm signatures in the auroral ionosphere rather than in the magnetosphere. Manual detection of the substorm phases always implies uncertainties of the order of several minutes depending on the data and the criteria. Different definitions should be thoroughly investigated in a future study. The du-

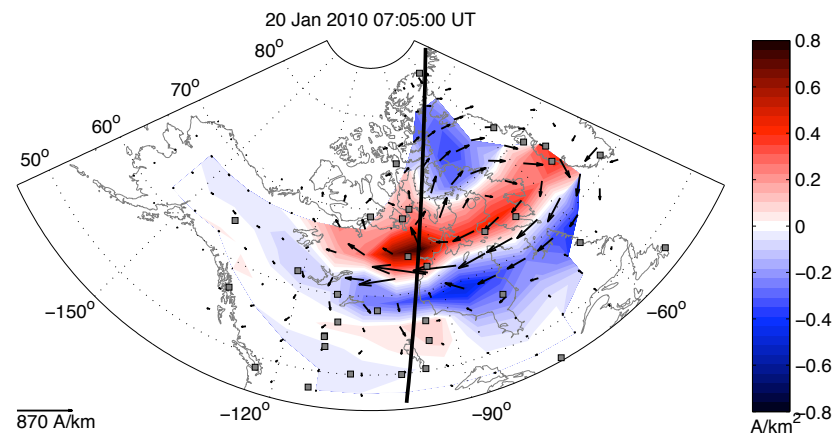

Fig. 4. Horizontal distribution of equivalent currents (black vectors) from the THEMIS, CARISMA, CANMOS, MACCS and Greenland magnetometer data during substorm 1 . The blue and red colours indicate FAC density up and down, respectively, estimated from the vorticity of the horizontal currents. The strongest currents occurred around the midnight meridian (black line) in the vicinity of the Harang reversal region at 07:05 UT. Gray squares mark the CARISMA magnetometer stations.

rations of the substorm phases in this paper are only meant to give an order of magnitude estimate. It is not our goal to precisely identify the substorm phases; however, we use the same identification method for each substorm in order to be able to compare specific quantities.

\subsection{Event 1: pre-storm substorm}

About $10 \mathrm{~h}$ prior to the beginning of the mini-storm main phase, a clear isolated average-sized substorm was observed at Rankin Inlet (RANK, 62.8 $8^{\circ}$ GLAT and 72.2 ${ }^{\circ}$ CGMLAT) in the Canadian sector on 20 January 2010. The onset took place at about 07:00 UT after an approximate three-hour long growth phase. The maximum negative deflection in the ground magnetic X-component was $-350 \mathrm{nT}$ during a 20-30 min long expansion phase, followed by a recovery of about $2.5 \mathrm{~h}$.

Ground-based measurements of indices and currents during event 1 are displayed in Fig. 3. The maximum westward electrojet current density reached $700 \mathrm{~mA} \mathrm{~m}^{-1}$ and resided around the geographic latitude of about $63^{\circ}$ but widened to cover about $10^{\circ}$ in latitude (bottom panel). The maximum eastward electrojet current density was $150 \mathrm{~mA} \mathrm{~m}^{-1}$ and was located both poleward $\left(\sim 70^{\circ}\right)$ and equatorward $\left(\sim 56^{\circ}\right)$ of the westward current region. The two-dimensional equivalent current distribution of the substorm expansion is displayed in Fig. 4. The maximum equivalent currents occurred at 07:05 UT, close to the noon-midnight meridian. Also present in Fig. 4 is the flow reversal of the dawnside convection cell (at $65^{\circ}-70^{\circ}$ GLAT) just east of Harang reversal region. The estimated current distribution places the onset at the poleward edge (at around $63^{\circ}$ GLAT) of the westward current region and at the edge of the region of upward field-aligned current (FAC). 

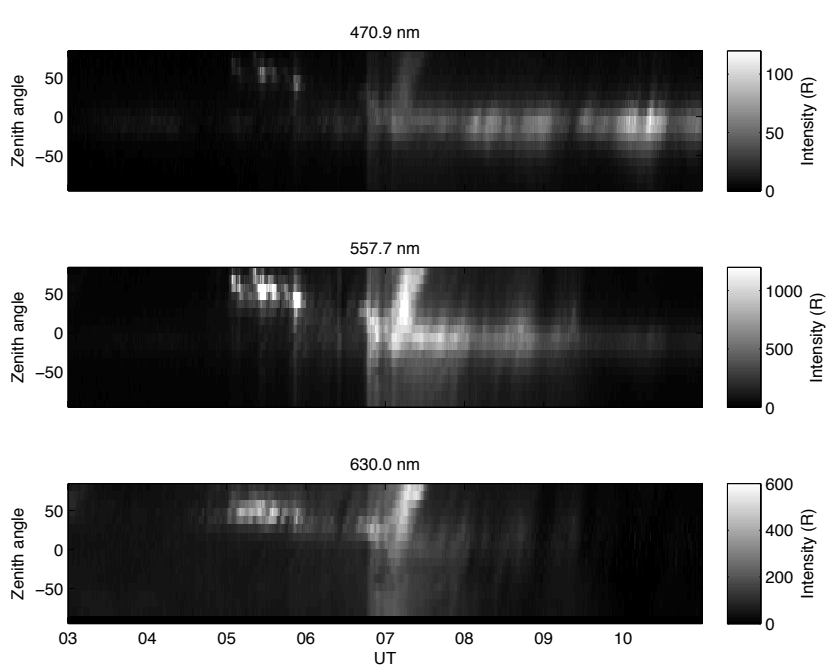

Fig. 5. MSP measurements at Gillam during substorm 1. Displayed auroral emissions have been captured at the wavelengths of $470.9 \mathrm{~nm}$ (top), $557.7 \mathrm{~nm}$ (middle) and $630.0 \mathrm{~nm}$ (bottom). The negative zenith angles are towards the south and positive towards the north (top of the panel).

Optical data were available from a NORSTAR Meridian Scanning Photometer (MSP) at Gillam (Fig. 5), which is located on the Churchill line south of RANK at $56.4^{\circ}$ GLAT. The MSP monitors auroral emissions at $557.7 \mathrm{~nm}$ (green), $630.0 \mathrm{~nm}$ (red), $486.1 \mathrm{~nm}$ (proton, not shown) and $470.9 \mathrm{~nm}$ (blue) wavelength along north-south scans. Assuming an emission altitude of $110 \mathrm{~km}$, its FoV extends roughly from 49 to 63 GLAT (60-73 CGMLAT) with a time resolution of $30 \mathrm{~s}$. Thus, the northern leg of the scan recorded the expansion phase aurora above RANK. The peak emission intensities were up to $1.3 \mathrm{kR}$ for the green emission, about $500 \mathrm{R}$ for the red emission and about $60 \mathrm{R}$ for the blue line. Emission intensity ratios are often used to infer how hard or soft the precipitation is, or even to calculate the characteristic precipitation energies (e.g. Rees and Luckey, 1974). In this study, we only consider the relative intensities of different wavelengths. The rather weak blue emission (1/10 the intensity of the red emission and 1/20 that of the green line emission intensity) suggests primarily soft electron precipitation even during the substorm expansion phase.

No signature of an external triggering could be found in the solar wind or IMF parameters. The solar wind speed was steady and slow around $300 \mathrm{~km} \mathrm{~s}^{-1}$ for at least $3 \mathrm{~h}$ before and after the substorm onset. Furthermore, IMF $B_{\mathrm{Z}}$ remained almost constant between the -3 to $-2 \mathrm{nT}$ for at least $1.5 \mathrm{~h}$ before and after the onset time. Density or dynamic pressure measurements were not available for this time period, but all the available measured parameters were stable and within the average value range.
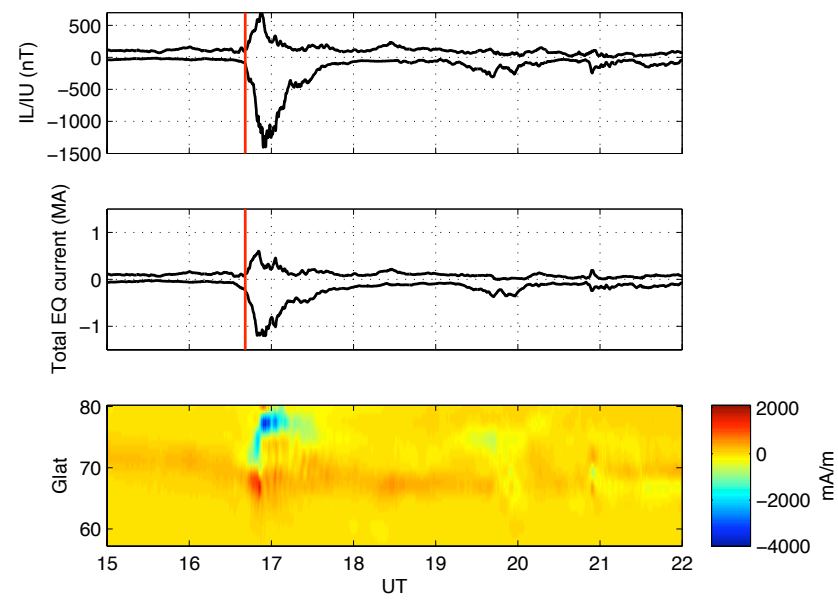

Fig. 6. Ground-based measurements during the storm main phase substorm (substorm 2) as a function of Universal Time. Panels from top to bottom: (1) auroral electrojet index (upper and lower) calculated from the IMAGE network, (2) strength of the total electrojet currents (eastward positive, westward negative) estimated from the magnetometer data, and (3) electrojet current density deduced from magnetometer recordings by 1-D upward continuation method (green/blue colours for westward and yellow/red colours for eastward).

\subsection{Event 2: main phase substorm}

The second substorm took place in the Fennoscandian sector at the very beginning of the mini-storm main phase. The fastest decrease of the Dst index took place during the storm main phase at 17:00-18:00 UT. The growth of substorm 2 began $2.3 \mathrm{~h}$ prior to the onset at $\sim 16: 40 \mathrm{UT}$. This was followed by an expansion phase of about $35 \mathrm{~min}$ and a recovery phase of about $1.8 \mathrm{~h}$. The maximum negative deflection of ground magnetic $B_{\mathrm{X}}$ component was about $830 \mathrm{nT}$ at $\$ \varnothing \mathrm{r} \varnothing y a$ (SOR, $70.5^{\circ}$ GLAT and $67.3^{\circ}$ CGMLAT) station in the IMAGE chain. The maximum intensity was more than double the intensity of substorm 1. Ground-based measurements similar to Fig. 3 are plotted in Fig. 6. The westward electrojet current reached the maximum current density of about $3.5 \mathrm{~A} \mathrm{~m}^{-1}$ (bottom panel). Also, an extensive poleward expansion of the westward electrojet was observed at substorm onset from the latitude of $70^{\circ}$ to the latitude of $78^{\circ}$ (bottom panel). The eastward current intensified to $\sim 1.5 \mathrm{~A} \mathrm{~m}^{-1}$ and expanded a few degrees equatorward at the end of the substorm growth phase. The separation of the maximum eastward and westward currents was almost $10^{\circ}$ in latitude, and the eastward current intensified earlier than the westward current. The horizontal equivalent current distribution (Fig. 7) of the expansion reveals strong eastward current in the mainland region, and a strong westward current at the coast and at the Svalbard latitudes (anti-sunward evening cell flow). As compared to substorm 1 in Sect. 2.1, this current configuration is more intense by about an order of magnitude. The structure appears 


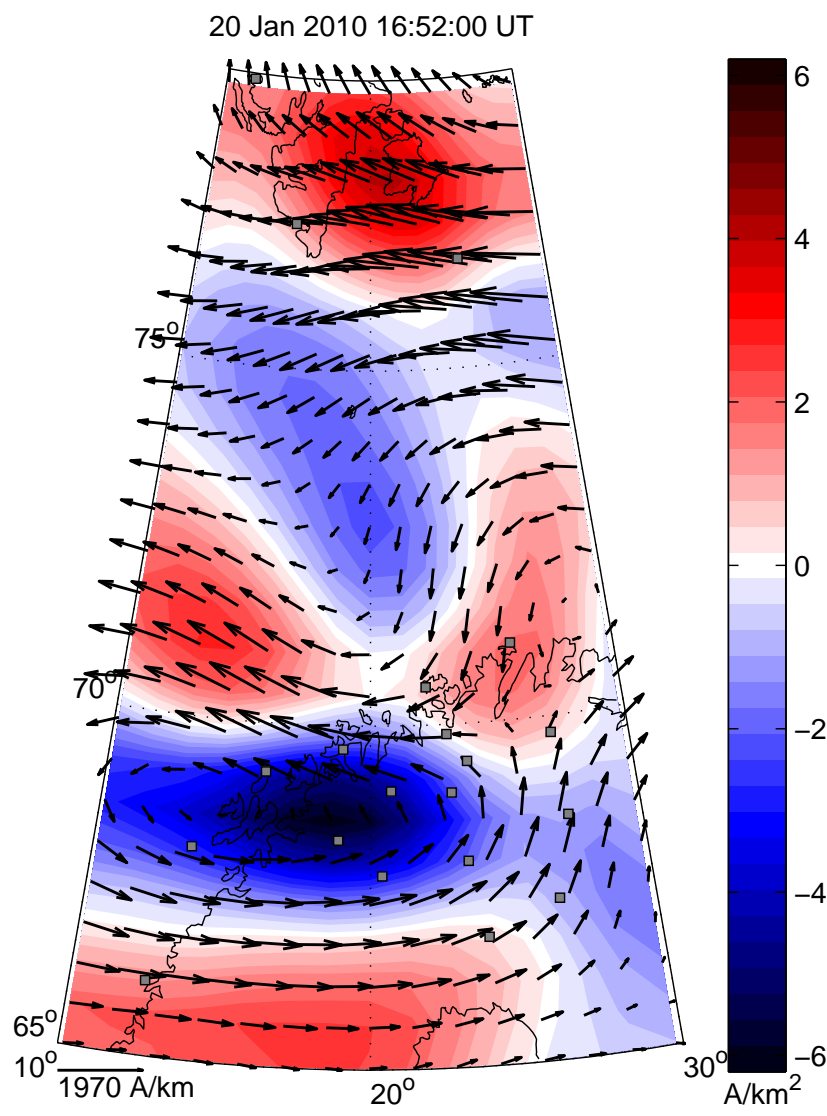

Fig. 7. Horizontal distribution of equivalent currents (black vectors) from the IMAGE magnetometer data during substorm 2. The blue and red colours indicate FAC density up and down, respectively, estimated as the vorticity of the horizontal currents. The strongest currents occurred in the onset region at 16:52 UT.

more complex than in the case of substorm 1. However, this is due to the better spatial resolution provided by the higher magnetometer station density of Fennoscandia. According to the vorticity estimate, the strongest upward FAC region during the substorm expansion was situated just south of the onset location. Some FACs in Fig. 7 can be due to the sparsely monitored region of the Arctic Ocean or the model area boundaries, but the strongest FACs occur over mainland, within good station coverage.

Optical data were available from a MIRACLE ASC in Longyearbyen on Svalbard. The station is located at the poleward boundary of the auroral oval but based on the 1-D equivalent current data (bottom panels of Fig. 6), the expansion reached the Svalbard latitudes (Longyearbyen at $78^{\circ}$ ) in less than $10 \mathrm{~min}$. Calibrated auroral intensities were not available for this time period, but the digital units (counts) for different emissions peaked at 255 (saturation) for green line, 180 for blue emission and 80 for red line, as shown in Fig. 8. In this event, the relative brightness of blue emission (over 2/3 of the green and more than twice as much as the red emission) is higher than in the case of substorm 1 . This sug-
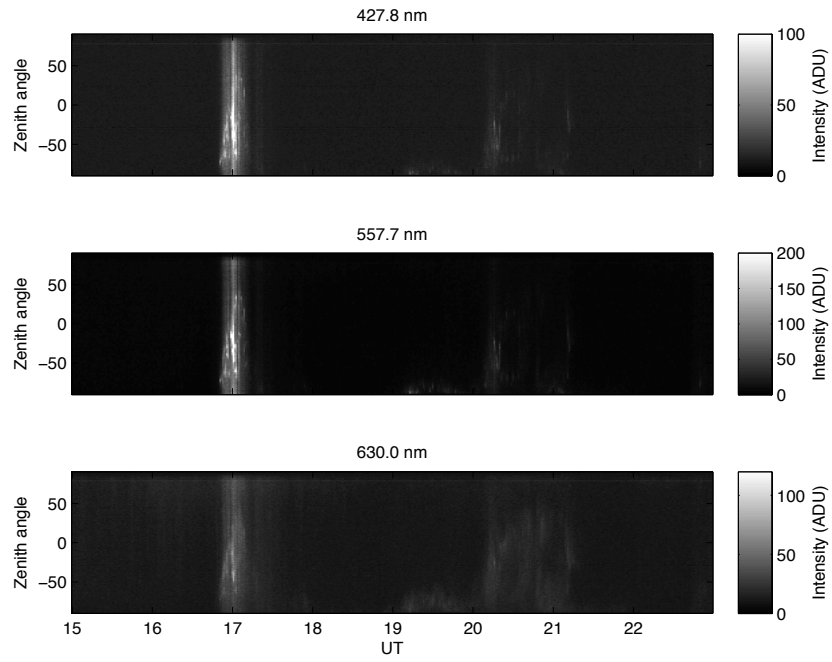

Fig. 8. ASC keograms from LYR station during substorm 2. Auroral emissions have been captured at the wavelengths of $427.8 \mathrm{~nm}$ (top), $557.7 \mathrm{~nm}$ (middle) and $630.0 \mathrm{~nm}$ (bottom). The negative zenith angles are towards the south and positive towards the north (top of the panel).

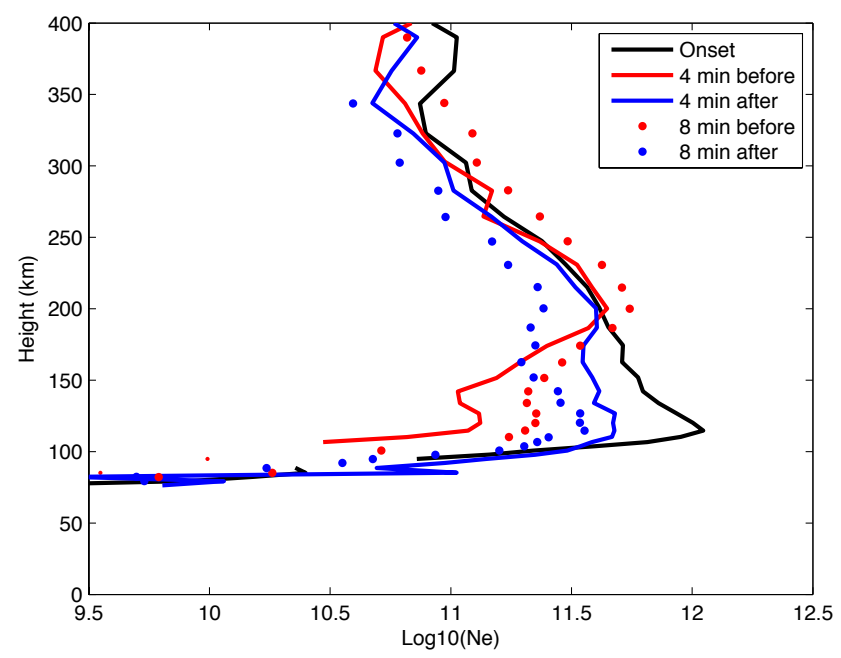

Fig. 9. Ionospheric electron density profiles as recorded by the EISCAT Troms $\emptyset$ radar during the early part of the expansion phase of substorm 2. The solid black line is the electron density at the time when the precipitation reaches the radar beam at 16:48 UT. The red line is the electron density $4 \mathrm{~min}$ earlier, and red dots $8 \mathrm{~min}$ earlier. Blue line is the electron density profile $4 \mathrm{~min}$ after and blue dots $8 \mathrm{~min}$ after, respectively.

gests much harder precipitation during the storm main phase as compared to the pre-storm substorm. This agrees with the EISCAT Troms $\varnothing$ measurements in Fig. 9 recorded at the beginning of the substorm expansion. The electron density in the F-region altitudes $(\sim 150-200 \mathrm{~km})$ was already elevated $10 \mathrm{~min}$ before the onset (red curves), while the E-region density at the altitude of $100-120 \mathrm{~km}$ only enhanced when 

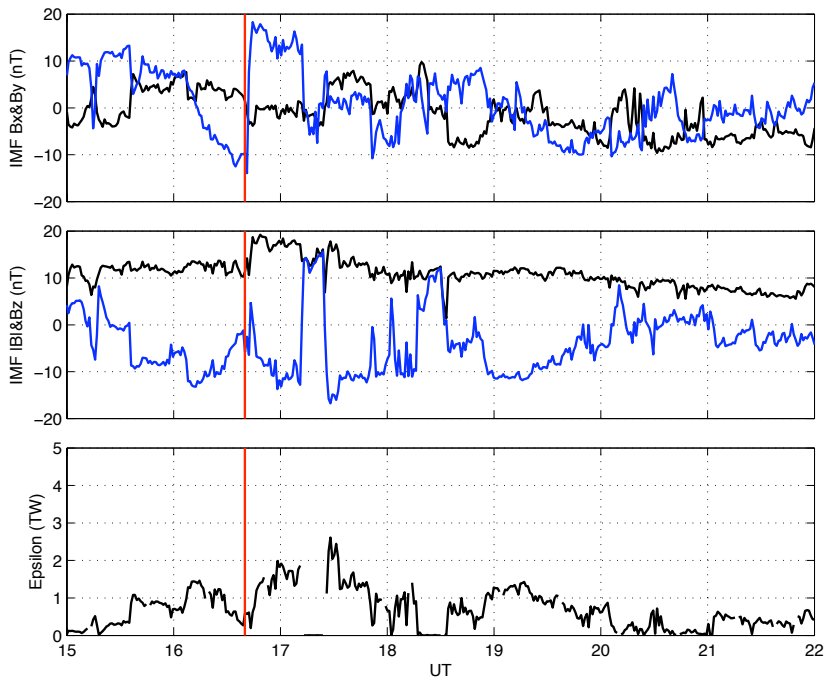

Fig. 10. IMF and solar wind parameters for substorm 2 in the main phase of the mini-storm. From the top to the bottom: (1) IMF $B_{X}$ (black) and $B_{Y}$ (blue), (2) IMF magnitude (black) and $B_{\mathrm{Z}}$ component (blue), and (3) epsilon parameter. The vertical red line marks the substorm onset time. These data are propagated to the magnetopause (at $10 R_{\mathrm{E}}$ ) with the average solar wind velocity.

the onset precipitation reached the radar beam at 16:48 UT (black curve). The electron density peak remained in the Eregion after the onset but the magnitude decayed within the next few minutes (blue curves). Several density enhancements were observed later during the day in accordance with the magnetic activity, but the most intense precipitation was captured during the substorm event 2. During the substorm onset, the electron density reached about $10^{12} \mathrm{~m}^{-3}$.

Further analysis of the EISCAT TRO data shows that the average ionospheric Hall-to-Pedersen conductance ratio, $\alpha$ during this substorm was 1.5 . During the substorm onset, $\alpha$ increased from 1 to 2 and then slowly decayed as the substorm recovery proceeded. The EISCAT Svalbard radar data suggests conductance ratios between 2.0-2.5 around the onset time. The conductances are integrated from 75 to $300 \mathrm{~km}$ altitude, and their calculations use a neutral atmospheric model MSIS2000 (Picone et al., 2002).

Prior to the onset time, the IMF $B_{\mathrm{Z}}$ had been negative for about $1.5 \mathrm{~h}$. At the onset time of substorm 2 (16:40 UT) the IMF $B_{Y}$ component turned from negative to positive (1st panel in Fig. 10), the IMF magnitude increased and the $B_{\mathrm{Z}}$ component briefly increased about $10 \mathrm{nT}$, but did not remain positive (2nd panel in Fig. 10). The dynamic pressure (solid line in the 2nd panel of Fig. 1) abruptly decreased by $5 \mathrm{nPa}$, producing a negative pressure impulse, while the solar wind speed increased by about $80 \mathrm{~km} \mathrm{~s}^{-1}$ (top panel in Fig. 1), but remained moderate. Unlike for the pre-storm substorm (event 1), the solar wind energy input to the magnetosphere (epsilon, bottom panel of Fig. 10) increased for substorm 2 onset and exceeded the storm loading threshold (1 TW) (Akasofu, 1981).
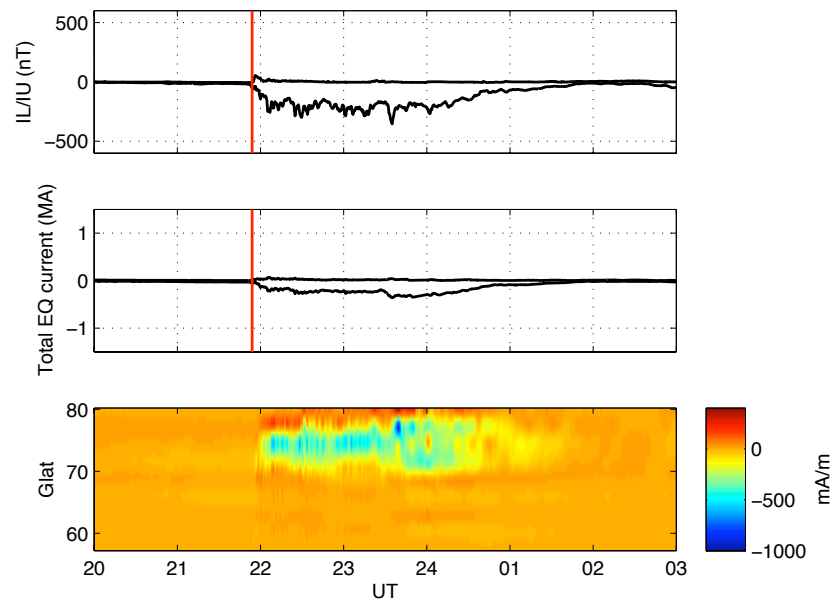

Fig. 11. Ground-based measurements during the storm recovery phase substorm (substorm 3) as a function of Universal Time. Panels from top to bottom: (1) auroral electrojet index (upper and lower) calculated from the IMAGE network, (2) strength of the total electrojet currents (eastward positive, westward negative) estimated from the magnetometer data, and (3) electrojet current density deduced from magnetometer recordings by 1-D upward continuation method (green/blue colours for westward and yellow/red colours for eastward).

\subsection{Event 3: storm recovery substorm}

Five days later when the mini-storm recovery phase was coming to an end, we chose a third substorm, which we will refer to as a storm-recovery phase substorm. The onset of this substorm occurred at 21:50 UT on 25 January 2010. The strongest magnetic deviations were observed at the Bear Island (BJN, 74.5 ${ }^{\circ}$ GLAT and 71.5 ${ }^{\circ}$ CGMLAT) station of the IMAGE network, which was located right at the Harang reversal region in the midnight sector. For this event, there was almost no growth phase at all according to the magnetogram from BJN station, and the expansion phase was composed of 4-5 substorm intensifications over $3 \mathrm{~h}$. The minima of the intensifications during the expansion was only about $-220 \mathrm{nT}$ at most but no clear recovery was observed before midnight. The recovery phase, when it finally began, also lasted for about $3 \mathrm{~h}$.

The ground-based data for substorm 3 is shown in Fig. 11 with the same format as for the substorms 1 and 2 . The westward electrojet intensified up to about $600 \mathrm{~mA} \mathrm{~m}^{-1}$ in the vicinity of the onset latitude. The width of the enhanced westward current region varied between $5^{\circ}$ and $8^{\circ}$ in latitude during the substorm activity. The eastward current strengthened at the latitudes of $77^{\circ}-78^{\circ}$ at the same time. The maximum eastward current density reached about $250 \mathrm{~mA} \mathrm{~m}^{-1}$, which is almost half the current density of the westward electrojet. The two-dimensional view of the equivalent currents (Fig. 12) displays the dominant westward current at the latitudes of the Arctic Ocean and weak eastward current over 


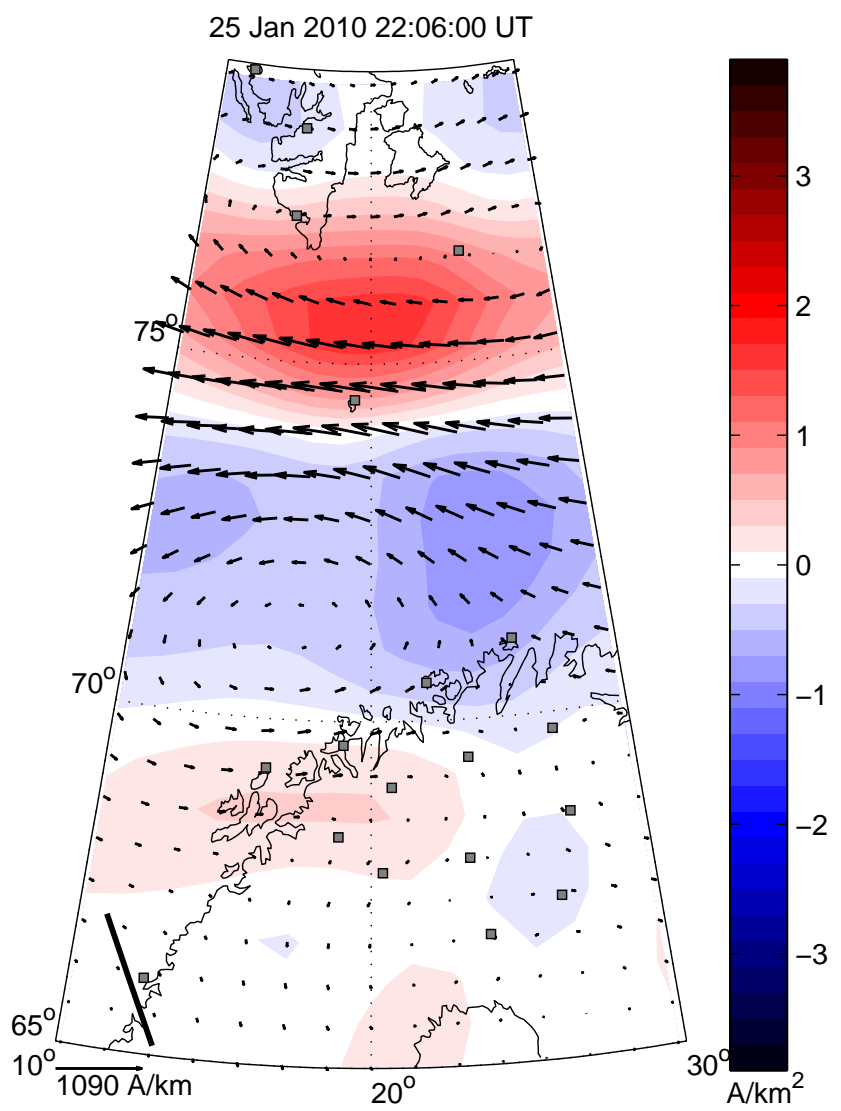

Fig. 12. Horizontal distribution of equivalent currents (black vectors) from the IMAGE magnetometer data during substorm 3. The blue and red colours indicate field-aligned current density up and down, respectively, estimated as the vorticity of the horizontal currents. The strongest currents occurred in the onset region at 22:06 UT.

Svalbard (anti-sunward flow) and the mainland. The region of substorm activity appeared in the sector just east of the midnight meridian (solid black line in the figure). The equivalent current pattern was simple during this onset compared to substorm 2.

No optical data were available for this event due to the cloud cover both over the mainland and the Svalbard stations. EISCAT UHF radar in Troms $\emptyset$ recorded small precipitation bursts at about $100 \mathrm{~km}$ in altitude between 13:00 and 16:00 UT. The more intense precipitation that began during the substorm onset, continued until midnight. At the beginning of the expansion phase, the radar probed the shear flow region between the oppositely directed electrojets. Figure 13 illustrates that the peak altitude of the electron density occurred at around $110-120 \mathrm{~km}$. The electron density peak remained around $5 \times 10^{11} \mathrm{~m}^{-3}$ and even the F-region values were half a magnitude lower than those observed during substorm 2.

The ionospheric conductance ratio $\alpha$ deduced from the EISCAT TRO data reached a maximum value of only 1.4

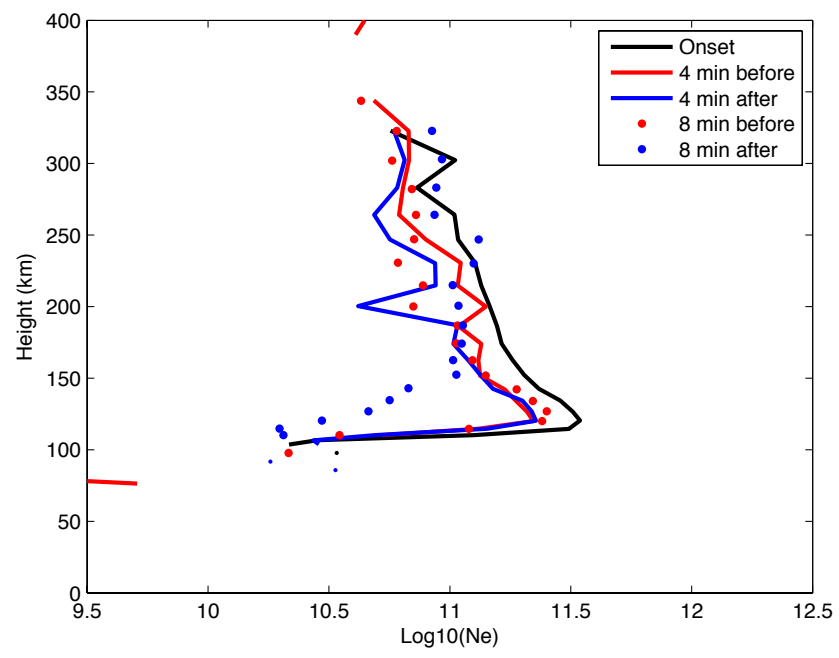

Fig. 13. Ionospheric electron density profiles as recorded by the EISCAT Troms $\varnothing$ radar at the onset of substorm 3. The solid black line is the electron density at the time when the radar beam encountered the precipitation at 22:11 UT. The red curve shows the electron density 4 min earlier, and red dots 8 min earlier. The blue curve indicates the electron density profile $4 \mathrm{~min}$ after and blue dots $8 \mathrm{~min}$ after, respectively.

during this event. The average conductance ratio was 1.3. Typically this ratio ranges from 1 to 2 . The observed difference between the expansions of substorms 2 and 3 is $20 \%$. The conductance ratio calculated from the EISCAT Svalbard radar data was at 1.5-2.0 after 23:00 UT when the expansion reached the high Arctic. The ratio was also smaller than that observed with the radar during substorm 2 .

The solar wind parameters (data not shown, apart from $V_{\text {SW }}$ and $p_{\text {dyn }}$ in Fig. 1) for substorm 3 were very steady. The speed was slow and stable around $370-380 \mathrm{~km} \mathrm{~s}^{-1}$ for several hours, the dynamic pressure remained around $1 \mathrm{nPa}$ for the whole activity period, and the IMF $B_{\mathrm{Z}}$ stayed at about $-3 \mathrm{nT}$ for $1.5 \mathrm{~h}$ before and after the substorm onset. There were no obvious discontinuities in the solar wind during this substorm and the epsilon parameter did not exceed a typical substorm input level of $0.1 \mathrm{TW}$.

\section{Event summary and discussion}

The entire month of January 2010 was magnetically quiet apart from a mini-storm on 20 January through 26-27 January when the Dst index reached its minimum of $-38 \mathrm{nT}$ on 20 January. The recovery of this mini-storm lasted about 6 6.5 days. Table 1 summarizes the main parameters describing the three substorm events analysed in this study.

Our pre-storm substorm (substorm 1) occurred about $10 \mathrm{~h}$ before the storm began. After such a quiet month and during slow and steady conditions in the solar wind, the recovery phase of the substorm lasted about $2.5 \mathrm{~h}$. The pre-storm 
substorm expansion phase showed an average substorm AL minimum of about $-350 \mathrm{nT}$, and the maximum eastward current density was only $1 / 4$ of the westward current density. The red emission during this substorm appeared to be ten times as intense as the blue emission, suggesting very soft electron precipitation during the expansion phase.

According to the AE index, the most intense activity of the month occurred in the early evening of 20 January and was associated with our substorm 2 . AE reached almost $1000 \mathrm{nT}$ and $\mathrm{AL}$ decreased to about $-700 \mathrm{nT}$ just prior to the steepest decrease of Dst at 18:00 UT. The storm minimum value of $-38 \mathrm{nT}$ was recorded a few hours later at 23:00 UT. During the couple of days prior to the storm onset, the Kp index was very low, close to zero, while at the mini-storm onset it rapidly increased to 4 . A prolonged period of very quiet time before a CIR/HSS driven geomagnetic storm has been called the calm before the storm by, e.g. Borovsky and Steinberg (2006). The calms have been investigated as a way to precondition the magnetosphere for the storm, and affecting, for instance, the particle population of the outer magnetosphere and further the behaviour of the ring current.

The main phase substorm (substorm 2) was much more intense than the other two substorms studied here. The maximum magnetic deflection was $2-3$ times larger $(\sim-800 \mathrm{nT})$ than for the other two events, and the electrojet current density maxima were approximately an order of magnitude larger than the maxima recorded during the other substorm events. Furthermore, this substorm began earlier in the MLT evening sector as compared to the two other events, and the largest ground deflections were recorded at lower magnetic latitudes during the storm than prior to it. Auroral precipitation during the expansion phase of substorm 2 was very hard, judging by the intensity of the blue line emission seen in the all-sky camera data (twice as intense as the red line) and the large electron density maximum at the altitude of about $100 \mathrm{~km}$ as recoded by the EISCAT radar. Although the energy dissipation during the expansion phase was very intense, the substorm recovery phase lasted almost $2 \mathrm{~h}$. Based on the EISCAT measurements, the electron density during the storm main phase was about twice the electron density during the storm recovery.

The energy input from the solar wind exceeded the storm loading threshold ( $1 \mathrm{TW}$ ) for substorm 2, while for the other two events it barely reached the substorm input threshold $(0.1 \mathrm{TW})$. Substorm 2 was also the only one of our three events where a solar wind trigger was found. In the solar wind we observed a change in sign of the IMF $B_{Y}$ component, an increase in magnitude of IMF and abruptly decreasing solar wind dynamic pressure, which is a signature of a stream interface (Gosling et al., 1978). The studies by Hsu and McPherron (2003) and Kullen et al. (2010) show that 50$60 \%$ of the substorms are associated with a potential IMF $B_{\mathrm{Z}}$ or $B_{\mathrm{Y}}$ trigger. Furthermore, large changes in the dynamic pressure $(>7 \mathrm{nPa}$ ) are only responsible for a fraction (1-3\%) the largest substorms. As the most intense substorm events often occur during magnetic storms, the pressure triggered group of substorms may be related to the geomagnetic storm main phases and the storm triggering.

Several substorms took place during the prolonged recovery of the mini-storm. We examined one of the last ones, which appeared as a 3-h burst of substorm intensifications. This peculiar substorm (substorm 3) had no real growth phase, an extensive expansion phase with multiple (4-5) intensifications and an equally long recovery phase. None of the substorm intensifications $(\sim-220 \mathrm{nT})$ were particularly intense. This kind of prolonged activity in the auroral region is characteristic for CIR/HSS storms during the solar minimum years (Tsurutani et al., 2006). During the recovery phase of a fully developed storm, a long-lived and intense recovery activity period can be referred to as High-Intensity Long-Duration Continuous AE Activity (HILDCAA, Tsurutani and Gonzalez, 1987). It was concluded that HILDCAA is driven by the Alfvén wave activity (IMF $B_{Z}$ fluctuations) in the high-speed solar wind. In the mini-storm case, the $\mathrm{AE}$ intensity criteria of HILDCAA are not fulfilled and the maximum solar wind speed of about $500 \mathrm{~km} \mathrm{~s}^{-1}$ does not, strictly speaking, qualify as HSS. But in the smaller scale the phenomenon is similar to the long-lasting electrojet activity and fluctuating IMF $B_{Z}$.

In the case of substorm 3, the auroral and electrojet activity continued for about $3 \mathrm{~h}$. The solar wind energy input had already reduced to values around $0.1 \mathrm{TW}$. While substorm 2 was clearly directly driven by the high energy input of the solar wind, the energy that dissipated during the prolonged substorm activity had to come mainly from the magnetotail storage. It seems likely that the directly driven part of the substorm activity during the storm recovery decreases as the solar wind input decreases; and at the very end of the storm recovery, substorms are able to dissipate any remnants of the stored energy. Extended substorm activity has been suggested to prevent the recovery of the Dst index at the end of the magnetic storm (Tsurutani and Gonzalez, 1997). Earthward motion of the plasma sheet or an intensification of the plasma sheet current could also be a candidate for preventing the ring current recovery. According to Milan (2009), the magnetic perturbation related to the ring current activity may choke the nightside reconnection and stop the auroral oval from contracting until the ring current dissipates. As concluded by Turner et al. (2009), the CIR storms couples the solar wind very efficiently to the magnetosphere-ionosphere system, and the dominant energy dissipation processes are the ionospheric processes: auroral precipitation and Joule heating. Our results on soft precipitation during the storm recovery substorm suggest that the ionospheric dissipation is mainly due to high fluxes of low energy particles that keep the auroral and electrojet activity going. A smaller fraction of injected particles during substorm 3 ends up in the ring current region, since the Dst index returns to the values close to zero earlier than the AL/AU indices settle (Fig. 1). 
Table 1. Summary of substorms 1, 2 and 3.

\begin{tabular}{lccc}
\hline & Pre-storm (1) & Main phase (2) & Recovery (3) \\
\hline Max $\Delta B_{\mathrm{X}}$ & $-350 \mathrm{nT}$ & $-830 \mathrm{nT}$ & $-220 \mathrm{nT}$ \\
Growth $t$ & $3 \mathrm{~h}$ & $2.3 \mathrm{~h}$ & $0 \mathrm{~min}$ \\
Expansion $t$ & $20-30 \mathrm{~min}$ & $35 \mathrm{~min}$ & $3 \mathrm{~h}$ \\
Recovery $t$ & $2.5 \mathrm{~h}$ & $1.8 \mathrm{~h}$ & $3 \mathrm{~h}$ \\
Onset MLT & $00: 30$ & $20: 40$ & $00: 30$ \\
Onset Mlat & $72.2^{\circ}$ & $67.3^{\circ}$ & $71.5^{\circ}$ \\
\hline
\end{tabular}

As required by the search criteria all three substorms displayed were an enhancement of the auroral electrojets. For two of the substorms both the eastward and the westward currents strengthened simultaneously, while during substorm 2 the eastward electrojet intensified earlier than the westward one. This may relate to the location of substorm 2 in the evening sector west of the Harang reversal region. The other two events occurred in the midnight sector just east of the Harang reversal.

One of the differences between isolated and storm-time substorms found by Hoffman et al. (2010) was that the stormtime auroral emission intensities are about double as compared to the emission intensities during isolated substorms. Our precipitation and emission measurements during the isolated pre-storm substorm and the storm recovery substorm both suggest soft particles as the dominant component. Because the radar field-of-view is only of the order of one degree, there is the possibility that the ionospheric column within the radar field-of-view does not capture the strongest enhancements of electron density during the substorm. However, as much as we can tell from the ground magnetic measurements, the expansion activity does pass over the radar site during substorms 2 and 3. Since we chose the electron density profiles with highest peak values rather than the ones exactly at the onset time, the spatial uncertainty has been minimized. Unfortunately, optical auroral data were not available for all three events and thus, a direct comparison of the emission intensities was not possible.

\section{Summary and conclusions}

Three substorms, each during a different phase of a small geomagnetic storm on 20-26 January 2010, have been examined and their characteristics compared. As summarised by the substorm key parameters in Table 1, the pre-storm event is an average isolated non-stormtime substorm, although above average in duration. As soon as the storm main phase started, the duration of the substorm activity decreased by about an hour and was significantly more intense due to the available solar wind energy. The main phase substorm 2 occurred a few degrees lower in latitude than the two other events. This substorm was directly driven by solar wind en- ergy input that exceeded the storm loading threshold of 1 TW. The storm recovery phase substorm 3 was below average in intensity, but its expansion phase displayed multiple intensifications and was above average in duration, which suggests very intense Joule heating compared to the other events. This observation is in agreement with Tsurutani and Gonzalez (1997) who reported that the slow recovery of a storm is a signature of a large energy storage of the magnetotail. New particle injections keep the substorm activity going and the ring current enhanced. As a result, the storm recovery is being delayed.

The pre-storm substorm (event 1) aurora was dominated by green and red emission with very weak blue emission component indicating mainly soft precipitation. The electron density profiles of event 3 that peaked above $100 \mathrm{~km}$ were also indicative of primarily soft electrons. Similarity of the weak blue emission line during the pre-storm substorm and precipitation characteristics during the storm recovery phase substorm suggest that the two substorms are associated with soft particle precipitation. However, the storm main phase substorm (event 2 ) included a very strong blue emission line and an intense electron density peak at the height of $100 \mathrm{~km}$, implying both a high flux of precipitating electrons and the presence of a higher energy electron population.

While the auroral emission and precipitation observations are in agreement with Hoffman et al. (2010), the substorm expansion durations during the different phases of the storm differ from the Hoffman et al. (2010) averages. Both the prestorm and the storm main phase events in this study show an expansion phase of about $30 \mathrm{~min}$, which is the average isolated substorm expansion phase duration in the study by Hoffman et al. (2010) and twice as long as their average substorm expansion time during a storm main phase. The storm recovery phase substorm (event 3 ) lasted longer than any of the substorms in 1993-2003 (Tanskanen, 2009). Because the solar wind energy input had ended earlier in the storm recovery phase, the large amount of energy dissipated during the substorm intensifications of event 3 had to come from the magnetospheric storage.

The intense nature of the storm main phase substorm is obvious and intuitively clear given the strong solar wind driving of a geomagnetic storm. The results of the mini-storm studied in this paper suggest that the substorm activity during the storm recovery phase plays a key role in dissipating the remnants of the storm energy and thus, may show very different behaviour from isolated substorm events. We observed very short growth, long-lasting expansion and recovery, and more complex expansion with multiple intensifications. Producing this kind of a substorm event during non-storm conditions would require a significant energy input from the solar wind, which was not present during the recovery phase of the ministorm. Further work is required to statistically characterise the storm recovery phase substorms. 
Acknowledgements. We thank the institutes who maintain the IMAGE Magnetometer Array. The authors thank I. R. Mann and the CARISMA team for data. CARISMA is operated by the University of Alberta, funded by the Canadian Space Agency. For the Greenland magnetometer data we thank Jürgen Matzka from the Technical University of Denmark in Copenhagen. CANMOS data were provided by David Calp of Natural Resources Canada. For MACCS data the authors thank Augsburg College, US. Dst index data are downloaded from the World Data Center for Geomagnetism in Kyoto at http://wdc.kugi.kyoto-u.ac.jp. Operational support for NORSTAR is provided by the Canadian Space Agency. We acknowledge the NORSTAR team for providing the meridian scanning photometer data used in this study.

The FMI authors acknowledge the financial support by the Academy of Finland, projects 115947, 128189, 128632, 108518 and 137900. The work of NP is supported by the Finnish Graduate School in Astronomy and Space Physics.

Topical Editor R. Nakamura thanks J. W. Gjerloev and A. Kullen for their help in evaluating this paper.

\section{References}

Akasofu, S.-I.: Energy coupling between the solar wind and the magnetosphere, Space Sci. Rev., 28, 121-190, 1981.

Amm, O.: Ionospheric elementary current systems in spherical coordinates and their application, J. Geomagn. Geoelectr., 49, 947955, 1997.

Amm, O. and Viljanen, A.: Ionospheric disturbance magnetic field continuation from the ground to the ionosphere using spherical elementary current systems, Earth Planets Space, 51, 431-440, 1999.

Borovsky, J. E. and Steinberg, J. T.: The "calm before the storm" in CIR/magnetosphere interactions: Occurrence statistics, solar wind statistics, and magnetospheric preconditioning, J. Geophys. Res., 111, A07S10, doi:10.1029/2005JA011397, 2006.

Borovsky, J. E., Nemzek, R. J., and Belian, R. D.: The occurrence rate of magnetospheric-substorm onsets: random and periodic substorms, J. Geophys. Res., 98, 3807-3813, 1993.

Denton, M. H., Borovsky, J. E., Skoug, R. M., Thomsen, M. F., Lavraud, B., Henderson, M. G., McPherron, R. L., Zhang, J. C., and Liemohn, M. W.: Geomagnetic storms driven by ICMEand CIR-dominated solar wind, J. Geophys. Res., 111, A07S07, doi:10.1029/2005JA011436, 2006.

Donovan, E. F., Trondsen, T. S., Cogger, L. L., and Jackel, B. J.: All-sky imaging within the Canadian CANOPUS and NORSTAR projects, Sodankylä Geophysical Observatory publications, 92, 109-112, 2003.

Engebretson, M. J., Hughes, W. J., Alford, J. L., Zesta, E., Cahill Jr., L. J., Arnoldy, R. L., and Reeves, G. D.: Magnetometer array for cusp and cleft studies observations of the spatial extent of broadband ULF magnetic pulsations at cusp/cleft latitudes, J. Geophys. Res., 100, 19371-19386, doi:10.1029/95JA00768, 1995.

Frank, L. A., Sigwarth, J. B., Craven, J. D., Cravens, J. P., Dolan, J. S., Dvorsky, M. R., Hardebeck, P. K., Harvey, J. D., and Muller, D. W.: The visible imaging system (VIS) for the Polar spacecraft, Space Sci. Rev., 71, 297-328, 1995.

Gjerloev, J. W., Hoffman, R. A., Sigwarth, J. B., and Frank L. A.: Statistical description of the bulge-type auroral sub- storm in the far ultraviolent, J. Geophys. Res., 112, A07213, doi:10.1029/2006JA012189, 2007.

Gonzalez, W. D., Joselyn, J. A., Kamide, Y., Kroehl, H. W., Rostoker, G., Tsurutani, B. T., and Vasyliunas, V. M.: What is a geomagnetic storm?, J. Geophys. Res., 99, 5771-5792, 1994.

Gosling, J. T., Asbridge, J. R., Bame, S. J., and Feldman, W. C.: Solar wind stream interfaces, J. Geophys. Res., 83, 1401-1412, 1978.

Greenwald, R. A., Baker, K. B., Dudeney, J. R., Pinnock, M., Jones, T. B., Thomas, E. C., Villain, J.-P., Cerisier, J.-C., Senior, C., Hanuise, C., Hunsucker, R. D., Sofko, G., Koehler, J., Nielsen, E., Pellinen, R., Walker, A. D. M., Sato, N., and Yamagishi, H.: Darn/Superdarn: A Global View of the Dynamics of HighLattitude Convection, Space Sci. Rev., 71, 761-796, 1995.

Hoffman, R. A., Gjerloev, J. W., Frank, L. A., and Sigwarth, J. W.: Are there optical differences between storm-time substorms and isolated substorms?, Ann. Geophys., 28, 1183-1198, doi:10.5194/angeo-28-1183-2010, 2010.

Hsu, T.-S. and McPherron, R. L.: Occurrence frequencies of IMF triggered and nontriggered substorms, J. Geophys. Res., 108, 1307, doi:10.1029/2002JA009442, 2003.

Kallio, E. I., Pulkkinen, T. I., Koskinen, H. E. J., Viljanen, A., Slavin, J. A., and Ogilvie, K.: Loading-unloading process in the nightside ionosphere, Geophys. Res. Lett., 27, 1627-1630, 2000.

Kissinger, J., McPherron, R. L., Hsu, T.-S., and Angelopoulos, V.: Steady magnetospheric convection and stream interfaces: Relationship over a solar cycle, J. Geophys. Res., 116, A00I19, doi:10.1029/2010JA015763, 2011.

Kullen, A. and Karlsson, T.: On the relation between solar wind, pseudobreakups, and substorms, J. Geophys. Res., 109, A12218, doi:10.1029/2004JA010488, 2004.

Kullen, A., Karlsson, T., Cumnock, J. A., and Sundberg, T.: Occurrence and properties of substorms associated with pseudobreakups, J. Geophys. Res., 115, A12310, doi:10.1029/2010JA015866, 2010.

McPherron, R. L.: Growth phase of magnetospheric substorms, J. Geophys. Res., 75, 5592-5599, 1970.

Milan, S. E.: Both solar wind-magnetosphere coupling and ring current intensity control of the size of the auroral oval, Geophys. Res. Lett., 36, L18101, doi:10.1029/2009GL039997, 2009.

Partamies, N., Pulkkinen, T. I., McPherron, R. L., McWilliams, K., Bryant, C. R., Tanskanen, E., Singer, H. J., Reeves, G. D., and Thomsen, M. F.: Different magnetospheric modes: solar wind driving and coupling efficiency, Ann. Geophys., 27, 4281-4291, doi:10.5194/angeo-27-4281-2009, 2009.

Perreault, P. and Akasofu, S.-I.: A study of geomagnetic storms, Geophys. J. R. Astr. Soc., 54, 547-573, 1978.

Picone, J. M., Hedin, A. E., Drob, D. P., and Aikin, A. C.: NRLMSISE-00 empirical model of the atmosphere: Statistical comparisons and scientific issues, J. Geophys. Res., 107, 1468, doi:10.1029/2002JA009430, 2002.

Pulkkinen, T. I., Partamies, N., McPherron, R. L., Henderson, M., Reeves, G. D., Thomsen, M. F., and Singer, H.: Statistical analysis of stormtime activations and sawtooth events, J. Geophys. Res., 112, A01205, doi:10.1029/2006JA012024, 2007.

Pulkkinen, T. I., Tanskanen, E., Viljanen, A., Partamies, N., and Kauristie, K.: Auroral electro jets during deep solar minimum at the end of solar cycle 23, J. Geophys. Res., 116, A04207, doi:10.1029/2010JA016098, 2011. 
Rees, M. H. and Luckey, D.: Auroral electron energy derived from ratio of spectroscopic emissions, 1. Model computations, J. Geophys. Res., 79, 5181-5186, 1974.

Rostoker, G., Samson, J. C., Creutzberg, F., Hughes, T. J., McDiarmid, D. R., McNamara, A. G., Vallace Jones, A., Wallis, D. D., and Cogger, L. L.: CANOPUS - A ground based instrument array for remote sensing in the high latitude ionosphere during ISTP/GGS program, Space Sci. Rev., 71, 743-760, 1995.

Syrjäsuo, M., Pulkkinen, T. I., Janhunen, P., Viljanen, A., Pellinen, R. J., Kauristie, K., Opgenoorth, H. J., Wallman, S., Eglitis, P., Karlsson, P., Amm, O., Nielsen, E., and Thomas, C.: Observations of substorm electrodynamics using the MIRACLE network, in Substorms-4, edited by: Kokubun, S. and Kamide, Y., Terra Scientific Publishing Company, Tokyo, 111, 1998.

Tanskanen, E.: A comprehensive high-throughput analysis of substorms observed by IMAGE magnetometer network: Years 1993-2003, J. Geophys. Res., 114, A05204, doi:10.1029/2008JA013682, 2009.

Tanskanen, E., Koskinen, H. E. J., Pulkkinen, T. I., Slavin, J. A., and Ogilvie, K.: Dissipation to the joule heating: isolated and stormtime substorms, Adv. Space Res., 30, 2305-2311, 2002a.

Tanskanen, E., Pulkkinen, T. I., Koskinen, H. E. I., and Slavin, J. A.: Substorm energy budget during low and high solar activity: 1997 and 1999 compared, J. Geophys. Res., 107, 1086, doi:10.1029/2001JA900153, 2002b.

Torr, M. R., Torr, D. G., Zukic, M., Johnson, R. B., Ajello, J., Banks, P., Clark, K., Cole, K., Keffer, C., Parks, G., Tsurutani, B., and Spann, J.: A far-ultraviolet imager for international solarterrestrial physics mission, Space Sci. Rev., 71, 329-383, 1995.
Tsurutani, B. T. and Gonzalez, W. D.: The cause of high-intensity long-duration continuous AE activity (HILDCAAS) - Interplanetary Alfven wave trains, Planet. Space Sci., 35, 405-412, 1987.

Tsurutani, B. T. and Gonzalez, W. D.: The interplanetary causes of magnetic storms: A review, in: Geophysical Monograph, 98, American Geophysical Union, 1997.

Tsurutani B. T., Gonzalez, W. D., Gonzalez, A. L. C., Guarnieri, F. L., Gopalswamy, N., Grande, M., Kamide, Y., Kasahara, Y., Lu, G., Mann, I., McPherron, R., Soraas, F., and Vasyliunas, V.: Corotating solar wind streams and recurrent geomagnetic activity: A review, J. Geophys. Res., 111, A07S01, doi:10.1029/2005JA011273, 2006.

Turner, N. E., Cramer, W. D., Earles, S. K., and Emery, B. A.: Geoefficiency and energy partitioning in CIR-driven and CMEdriven storms, J. Atmos. Terr. Phys., 71, 1023-1031, 2009.

Vanhamäki, H., Amm, O., and Viljanen, A.: One-dimensional upward continuation of the ground magnetic field disturbance using spherical elementary current systems, Earth Planets Space, 55, 613-625, 2003.

Viljanen, A. and Häkkinen, L.: IMAGE magnetometer network. in: Satellite-Ground Based Coordination Sourcebook, edited by: Lockwood, M., Wild, M. N., and Opgenoorth, H. J., ESA publications SP-1198, 111-117, 1997.

Weygand, J. M., Amm, O., Viljanen, A., Angelopoulos, V., Murr, D., Engebretson, M. J., Gleisner, H., and Mann, I.: Application and validation of the spherical elementary currents systems technique for deriving ionospheric equivalent currents with the North American and Greenland ground magnetometer arrays, J. Geophys. Res., 116, A03305, doi:10.1029/2010JA016177, 2011. 